\title{
Regimen Used to Treat Bone Cancer
}

National Cancer Institute

\section{Source}

National Cancer Institute. Regimen Used to Treat Bone Cancer. NCI Thesaurus. Code C159440.

Any regimen that can be used for the treatment of bone cancer. 